\title{
A study on management of premature rupture of membranes
}

\author{
Arnab Mondal*, Sanhita Kanoongo
}

Department of Obstetrics and Gynecology, KPC Medical College and Hospital, Kolkata, West Bengal, India

Received: 14 January 2018

Accepted: 29 January 2018

\section{*Correspondence:}

Dr. Arnab Mondal,

E-mail: arnabbon@gmail.com

Copyright: (c) the author(s), publisher and licensee Medip Academy. This is an open-access article distributed under the terms of the Creative Commons Attribution Non-Commercial License, which permits unrestricted non-commercial use, distribution, and reproduction in any medium, provided the original work is properly cited.

\section{ABSTRACT}

Background: Premature rupture of membranes (PROM) is a common obstetric complication. Knowledge of etiopathogenesis, diagnosis, complications and management of PROM has significantly increased due to extensive research in the recent past. Yet, there is no unanimous opinion regarding optimum management of PROM. The aim of the study was to observe the patients during labor and compare the latent period, duration of first stage of labor, modes of deliveries and the use of oxytocin and its outcome in PROM cases with controls. The study has been conducted with the belief that these data will help in better management of PROM cases in future.

Methods: In this study, the definition of PROM adopted is rupture of fetal membranes before the onset of true labor pain. The minimum gestational age was taken to be 28 weeks. Diagnosis of PROM was mainly clinical. Patients were monitored during the latent period and during labor. Induction of labor was done where necessary. Collected data were analysed using Chi Square Test.

Results: It was observed that onset of labor was more rapid with increasing gestational age. Use of oxytocin for induction and augmentation of labor and operative deliveries were higher in PROM cases. These results mostly corroborated with the findings of other researchers.

Conclusions: The conclusion drawn at the end of the study was that individualized management of PROM cases depending on the gestational age and risk of complications is the best way to achieve a good fetomaternal outcome.

Keywords: Labor, Management, Membranes, Premature, Rupture

\section{INTRODUCTION}

Premature rupture of membranes (PROM) is a challenging problem to the obstetricians. During the last three decades it has taken a new dimension because of identification of clinical risk factors and improved fetomaternal outcome due to better management (use of antenatal corticosteroids, improved tocolysis, availability of safer antibacterial agents, safer modes of delivery and improved neonatal care). When membranes rupture before the onset of labor, it is known as premature rupture of membranes (PROM). When PROM occurs before 37 completed weeks of gestation it is termed as preterm premature rupture of membranes (p PROM). ${ }^{1}$ In majority of PROM cases approaching term, labor starts within 24 hours $(85-90 \%)$, but in $10-15 \%$ cases, labor may be delayed. When membranes remain ruptured for more than 24 hours (prolonged rupture of membranes) fetomaternal complications are substantial.

The latent period (time interval between rupture of membranes and onset of labor) is inversely proportional to the gestational age and directly proportional to the incidence of infection. Most of the problems of PROM are infection related and also due to gestational immaturity. Hence this study is directed towards optimum management of labor in PROM cases, and operative interventions, if necessary. 


\section{METHODS}

This cross-sectional case control study was conducted in the Department of Obstetrics and Gynecology, KPC Medical College and Hospital, Kolkata, over a period of 1 year (10/9/2013- 9/9/2014). Approval of the institutional ethics committee and informed consent from cases and controls included in the study were taken before conducting the study.

Study group consists of 100 cases with PROM with duration of gestational period beyond 28 completed weeks. Control group consists of 100 patients having rupture of membranes after the onset of true labor pain with duration of gestational period beyond 28 weeks. In both the groups, both booked and unbooked cases were included. Diagnosis of PROM was done from history, clinical examination and investigations.

Examination included inspection using Sim's posterior vaginal speculum. Aseptic per vaginal digital examination was done to exclude the possibility of cord or fetal limb prolapse and to assess cervical dilatation and effacement.

The patients were thoroughly monitored at regular intervals during latent period for the conditions of the mother and fetus. Preterm pregnancy was allowed to continue upto beginning of term except when there is cord or fetal limb prolapse, fetal distress, active labor and chorioamnionitis. If labor pain still failed to start, induction of labor was done. Term pregnancies were induced within 12-24 hrs if labor pain did not start by that time. Condition of the mother and fetus and progress of labor were observed and recorded in detail. Labor was induced or augmented where required. Lower segment caesarean section (L.S.C.S.), low forceps or ventouse operation were undertaken where required.

\section{Statistical analysis}

All data were recorded on an Excel spreadsheet and statistical analysis was done using Chi Square test.

\section{RESULTS}

Latent period or lag period was calculated from the time of rupture of membranes till the onset of true labor pain. Among 100 study cases, latent period was calculated in 67 cases. In 13 cases, L.S.C.S. was done before the onset of labor.

Indications of L.S.C.S. in these cases were previous twice L.S.C.S. (1 case), post Caesarean Section (C.S.) with breech presentation (1 case), transverse lie (2 cases), post C.S. with Intra Uterine Growth Retardation (IUGR) (1 case), breech presentation (3 cases) and fetal distress (5 cases). In 20 other cases, oxytocin drip was given to induce labor. So, these 33 cases were excluded during calculation of latent period.
Table 1: Calculation of latent period in 67 cases of PROM.

\begin{tabular}{|lll|}
\hline Latent period & No. of cases & Percentage \\
\hline$<8 \mathrm{hrs}$ & 28 & 41.8 \\
\hline $8-12 \mathrm{hrs}$ & 20 & 29.9 \\
\hline $12-24 \mathrm{hrs}$ & 13 & 19.4 \\
\hline$>24 \mathrm{hrs}$ & 6 & 9 \\
\hline
\end{tabular}

Table 1 shows that maximum number of patients with PROM (91\%) started labor within 24 hours after rupture of membranes.

Table 2: Latent period in primigravida and multigravida with PROM.

\begin{tabular}{|lll|}
\hline Latent period & Primigravida & Multigravida \\
\hline$<24 \mathrm{hrs}$ & $8(66.6 \%)$ & $53(96.4 \%)$ \\
\hline$>24 \mathrm{hrs}$ & $4(33.4 \%)$ & $2(3.6 \%)$ \\
\hline
\end{tabular}

It appears from Table 2 that majority of patients with PROM, both primi and multigravida, had latent period $<24 \mathrm{hrs}$

Table 3: Relation of gestational period with latent period in PROM cases.

\begin{tabular}{|lll|}
\begin{tabular}{|l} 
Gestational \\
period
\end{tabular} & $\begin{array}{l}\text { Latent period } \\
<24 \text { hrs }\end{array}$ & $\begin{array}{l}\text { Latent period } \\
>24 \text { hrs }\end{array}$ \\
\hline$<37$ weeks (4) & $1(25 \%)$ & $3(75 \%)$ \\
\hline$>37$ weeks (63) & $60(95.2 \%)$ & $3(4.8 \%)$ \\
\hline
\end{tabular}

It is seen from Table 3 that with increasing gestational age there is more rapid onset of labor. A Chi Square Test done on the Table 3 shows that for the obtained Chi Square value (22.63) and df 1 , the $\mathrm{p}$ value is $<0.05$. So, the fact that the onset of labor is more rapid with increasing gestational age is statistically significant.

Table 4: Modes of deliveries of the study group compared with control series.

\begin{tabular}{|lll|} 
& $\begin{array}{l}\text { Vaginal delivery } \\
\text { including assisted } \\
\text { breech delivery } \\
\text { (Non-operative) }\end{array}$ & $\begin{array}{l}\text { Operative } \\
\text { delivery } \\
\text { (forceps+L.S.C.S.) }\end{array}$ \\
\hline Study & 71 & $29(14+15)$ \\
\hline Control & 90 & $10(6+4)$ \\
\hline
\end{tabular}

It appears from Table 4 that there was increased rate of operative interferences in PROM cases $(29 \%)$ compared to controls (10\%). A Chi Square Test done on Table V shows that for the obtained Chi Square value (11.5) and df 1 , the $\mathrm{p}$ value is $<0.05$. So, the increase in operative modes of delivery in PROM cases compared to controls is found to be statistically significant. Here, 8 L.S.C.S. were done in primigravida and 5 L.S.C.S. in multigravida patients with PROM, before the onset of labor. 2 more women of the PROM group needed L.S.C.S. during labor 1 primi and 1 multigravida. 
Table 5: Use of oxytocin in the study cases and control group.

\begin{tabular}{|lll|}
\hline & $\begin{array}{l}\text { Oxytocin used for induction } \\
\text { and augmentation of labor }\end{array}$ & $\begin{array}{l}\text { Oxytocin } \\
\text { not used }\end{array}$ \\
\hline Study & $\begin{array}{l}56(20 \text { induction+36 } \\
\text { augmentation) }\end{array}$ & 31 \\
\hline Control & 11 (5 induction+6 augmentation) & 89 \\
\hline
\end{tabular}

From Table 5, we found that the use of oxytocin to induce and augment labor was more in PROM cases than the control series. A Chi Square Test done on Table VI shows that for the obtained Chi Square value (57.64) and df 1 , the $p$ value is $<0.05$. So, the increase in use of oxytocin for induction and augmentation of labor in PROM cases compared to controls is found to be statistically highly significant. Of the 56 PROM patients where oxytocin was used, 48 delivered vaginally and 8 by L.S.C.S. Of the 11 controls where oxytocin was used, 8 delivered vaginally and 3 by L.S.C.S.

Table 6: Duration of first stage of labor in study cases and control group.

\begin{tabular}{|lll|} 
& $\begin{array}{l}\text { Duration of } 1^{\text {st }} \text { stage } \\
<12 \text { hrs }\end{array}$ & $\begin{array}{l}\text { Duration of } 1^{\text {st }} \\
\text { stage }>12 \text { hrs }\end{array}$ \\
\hline \multirow{2}{*}{ Study } & $\begin{array}{l}67(77 \%) \\
(6 \text { primi+61 multi) }\end{array}$ & $\begin{array}{l}20(23 \%) \\
(11 \text { primi+9 multi) }\end{array}$ \\
\hline \multirow{2}{*}{ Control } & $\begin{array}{l}67(67 \%) \\
(2 \text { primi }+65 \text { multi) })\end{array}$ & $\begin{array}{l}33(33 \%) \\
(15 \text { primi }+18 \text { multi })\end{array}$ \\
\hline
\end{tabular}

It appears from Table 6 that the duration of 1st stage of labor is shortened with PROM. A Chi Square Test done on Table IV shows that for the obtained Chi Square value (2.3) and df 1 , the $p$ value is $>0.05$. So, the apparent shortening of duration of 1st stage of labor with PROM compared to control is not statistically significant.

Table 7: Incidence of intrapartum fetal distress in study and control series.

\begin{tabular}{|l|l|l|} 
& $\begin{array}{l}\text { Intrapartum fetal } \\
\text { distress }\end{array}$ & $\begin{array}{l}\text { No Fetal } \\
\text { distress }\end{array}$ \\
\hline Study & 7 & 93 \\
\hline Control & 4 & 96 \\
\hline
\end{tabular}

Table 7 shows that intrapartum fetal distress (manifested by fetal bradycardia, meconium stained liquor etc.) appears to be more in PROM cases than in the control group. A Chi Square Test done on Table 7 shows that for the obtained Chi Square value (0.87) and df 1 , the $\mathrm{p}$ value is $>0.05$. So, the apparent increase in intrapartum fetal distress in PROM cases compared to controls is not statistically significant.

Table 8 shows only 2 cases of cord prolapse in study group and no such cases in control group. A Chi Square Test done on Table VIII shows that for the obtained Chi Square value (2.02) and df 1 , the $\mathrm{p}$ value is $>0.05$. So, difference in occurrence of cord prolapse between the study and control groups is not statistically significant.

Table 8: Incidence of cord prolapse in study and control group.

\begin{tabular}{|lll|}
\hline Study & Cord prolapse & No cord prolapse \\
\hline Control & 2 & 98 \\
\hline
\end{tabular}

\section{DISCUSSION}

\section{Latent period}

In this series, majority of PROM cases went into spontaneous labor $(67 \%)$. This simulates the findings of Lebherz TB et al-61\%, Sacks et al-52.7\%, Conway DI$79 \%$, Raut MD et al-82.4\% and Cammu $\mathrm{H}$ et al-80$90 \% .^{2-6}$ This study shows that majority of patients with PROM have latent period $<24$ hrs (Table 1 ).

\section{Latent period and gravida status in PROM}

This study shows that majority of patients with PROM, both primi and multigravida have latent period $<24 \mathrm{hrs}$ (Table 2).

\section{Latent period and gestational age}

It is observed that latent period is inversely related to the gestational age when PROM has occurred (statistically significant). This finding is consistent with that of Donnelly JF (1957), who reported longer latent period with shorter gestational age (Table 3$)^{7}$

\section{Modes of deliveries of PROM cases}

In the present study, in the PROM group, vaginal deliveries were noted in $71 \%$ cases (Table 4 ). Sanyal MK et al reported $87 \%$ vaginal deliveries in PROM cases. ${ }^{8}$ In this study, forceps deliveries were undertaken in $14 \%$ of PROM cases and $7 \%$ of controls (mostly in fetal distress in second stage of labor, non-descent of presenting part and/or maternal distress in second stage of labor, or prolonged second stage of labor). The caesarean section rates reported by different authors in PROM patients are as follows: Schreiber J et al-24\%, Spinnato JA-15.4\%, Egan et al-8\% in primigravida, $2 \%$ in multigravida, Sanyal et al-3.5\%, Chua S et al-14.9-19.1\%, Shalev E et al-4.7-6.7\%, Ladfors L et al-2-4\%, Hannah ME et al-9.6$10.9 \% .^{8-15}$ Caesarean section was undertaken in $15 \%$ of PROM cases in the present series, which is nearly consistent with the findings of Spinnato JA, Chua $\mathrm{S}$ et al and Hannah ME et al. ${ }^{10,12,15}$ In the present study, the incidence of caesarean section among PROM cases was 1.5 times higher in primigravida than multigravida, which corroborates with the findings of Egan et al (section rate 4 times higher in primigravida). ${ }^{11}$ The incidence would have approached the reported 4 times higher in primigravida, but, it is only 1.5 times here because post 
caesarean pregnancies with obstetric complications were more common indications of caesarean section in multigravida PROM cases in the present study.

\section{Use of oxytocin in PROM cases}

In both PROM cases and controls where labor was induced or augmented with oxytocin, caesarean section was needed in a few cases for fetal distress or non progress of labor (Table 5). The requirement of oxytocin infusion for induction and augmentation of labor was found to be significantly more in PROM cases than controls in this study. The reason for this is that, if labor does not start within 12 hrs after rupture of membranes, chance of infection leading to maternal and neonatal morbidities will be higher. So, oxytocin infusion is widely used to manage such PROM cases. Continuation of oxytocin infusion depends on progress of labor, mostly upto $12 \mathrm{hrs}$.

\section{Duration of $1^{\text {st }}$ stage of labor}

The present study shows that the shortening of duration of 1st stage of labor with PROM compared to controls is not statistically significant (table 6). A study by Calkins LA showed that duration of 1st stage of labor is shortened with PROM. ${ }^{16}$ Traditional concept of role of the bag of membranes acting as cervical dilator is of great debate. In fact, Theobald GW pointed out that "the membranes are a liability rather than an asset" during labor. ${ }^{17}$ Apparent shortening of the duration of 1st stage of labor in PROM cases is probably due to direct pressure dilatation of the cervix by the presenting part.

\section{Intrapartum fetal distress}

The higher incidence of fetal distress in PROM cases compared to controls is not statistically significant, according to the present study (Table 7). The apparent higher incidence may be due to drainage of liquor leading to reduction of size of gravid uterus causing reduction of uteroplacental circulation, prematurity, infection, induction and augmentation with oxytocin.

\section{Cord prolapses}

Poorly fitting presenting part due to malpresentation, malpositions and non engaged presenting part may be the reasons for cord prolapse in PROM (Table 8). Occult cord prolapse is a distinct possibility. The results of the present study are not statistically significant, but higher number of case studies are essential to conclude the association of cord prolapse with PROM. Studies conducted by Russel et al, Sacks et al and Gunn et al reported overall incidence of cord prolapse in $0.3-0.5 \%$ of cases and in $2-4 \%$ of PROM cases..$^{3,18,19}$ The present study where $2 \%$ cord prolapse was detected in PROM cases was consistent with the incidence reported by above authors.

\section{CONCLUSION}

The following observations were made from the present study:

- Majority of PROM cases started labor within 24 hours of rupture of membranes and the onset of labor is more rapid with increasing gestational age

- Induction and augmentation of labor with slow oxytocin drip were more often needed during pregnancy and labor respectively in PROM cases.

- Majority of the PROM cases delivered vaginally, but the operative interferences were more often needed in PROM cases, when compared with controls.

Once PROM has occurred, controversy lies regarding whether or not to deliver the baby at that particular gestational age. The concern is that, not delivering the baby exposes the fetus to the risk of infection. Alternately, delivering the baby increases the risk of prematurity and its complications. Careful identification of present or impending complications, and individualizing the management based on gestational age and the presence or likelihood of these complications currently holds best hopes for optimizing fetomaternal outcome in PROM cases.

\section{ACKNOWLEDGMENTS}

Authors would like to acknowledge to all doctors and staff of Department of Obstetrics and Gynecology, KPC Medical College and Hospital for their sincere support and help.

\section{Funding: No funding sources Conflict of interest: None declared Ethical approval: Not required}

\section{REFERENCES}

1. McParland PC, Taylor DJ, Bell SC. Mapping of zones of altered morphology and choriodeciduaic connective tissue cellular phenotype in human fetal membranes (amnion and deciduas) overlying the lower uterine pole and cervix before labor at term. Am J Obstet Gynecol. 2003Nov;189(5):1481-8.

2. Lebherz TB, Hellman LP, Madding R, Anctil A, Arje SL. Double-blind study of premature rupture of the membranes. A report of 1896 cases. Am J Obstet Gynecol. 1963 Sep;87(2):218-25.

3. Sacks M, Baker TH. Spontaneous premature rupture of the membranes. A prospective study. Am J Obstet Gynecol. 1967 Apr;97(7):888-93.

4. Conway DI, Prendiville WJ, Morris A, Speller DCE, Stirrat GM. Management of spontaneous rupture of the membranes in the absence of labor in primigravid women at term. Am J Obstet Gynecol. 1984 Dec $15 ; 150(8): 947-51$. 
5. Raut MD, Dora H. PROM- A clinical and bacteriological study. J Obstet Gynaecol India. 1988;38:554-62.

6. Cammu H, Verlaenen H, Perde MP. Premature rupture of membranes at term in nulliparous women: a hazard?. Obstet Gynecol. 1990 Oct;76(4):671-4.

7. Donnelly JF, Flowers CE, Creadick RM, Greenberg BG, Wells HB. Parental, fetal, and environmental factors in perinatal mortality. Am J Obstet Gynecol. 1957 Dec;74(6):1245-56.

8. Sanyal MK, Mukherjee TN. Premature rupture of membranes an assessment from a rural medical college of West Bengal. J Obstet Gynaecol India. 1990;40(5):623-8.

9. Schreiber J, Benedetti T. Conservative management of preterm premature rupture of the fetal membranes in a low socioeconomic population. Am J Obstet Gynecol. 1980 Jan;136(1):92-6.

10. Spinnato JA, Shaver DC, Bray EM, Lipshitz J. Preterm premature rupture of the membranes with fetal pulmonary maturity present: A prospective study. Obstet Gynecol. 1987 Dec;25(6):489.

11. Egan D, O'hlerlihy C. Expectant management of spontaneous rupture of membranes at term. J Obstet Gynaecol. 1988 Jan;8(3):243-7.

12. Chua S, Arulkumaran S, Karup A, Anandakumar C, Tay D, Ratnam SS. Does prostaglandin confer significant advantage over oxytocin infusion for nulliparas with prelabor rupture of membranes at term? Obstet Gynecol. 1991 May;77:664-7.

13. Shalev E, Peleg D, Eliyahu S, Nahum Z. Comparison of 12-and 72-hour expectant management of premature rupture of membranes in term pregnancies. Obstet Gynecol. 1995 May;85(5 Pt 1):766-8.

14. Ladfors L, Mattson LA, Eriksson M, Fall O. A randomized trial of two expectant managements of prelabor rupture of the membranes at 34 to 42 weeks. Br J Obstet Gynaecol. 1996 Aug;103(8):755-62.

15. Hannah ME, Ohlsson A, Farine D, Hewson SA, Hodnett ED, Myhr TL et al. Induction of labor compared with expectant management for prelabor rupture of the membranes at term. TERM PROM Study Group. N Engl J Med. 1996 Apr 18;334(16):1005-10.

16. Calkins LA. Premature spontaneous rupture of the membranes. Am J Obstet Gynecol. 1952 Oct;64(4):871-7.

17. Theobald GW, Kelsey HA, Muirhead JMB. The pitocin drip. J Obstet Gynaecol Br Emp. 1956 Oct;63(5):641-62.

18. Russell KP, Anderson GV. The aggressive management of ruptured membranes. Am J Obstet Gynecol. 1962 Apr;83(7):930-7.

19. Gunn GC, Mishell DR Jr, Morton DG. Premature rupture of the fetal membranes. A review. Am J Obstet Gynecol. 1970 Feb;106(3):469-83.

Cite this article as: Mondal A, Kanoongo S. A study on management of premature rupture of membranes. Int J Reprod Contracept Obstet Gynecol 2018;7:8559. 